\title{
Extraction of Menthol using Different Methods from Peppermint Oil
}

\author{
Jaya Gade $^{1 *}$ and Snehal More ${ }^{2}$ \\ 'Department of Analytical Chemistry, SNDT Women's University, Santacruz, \\ Mumbai, India ${ }^{1}$ \\ ${ }^{2}$ Department of Oils, Oleochemicals \& Surfactant Technology, Institute of Chemical \\ Technology, Mumbai, India
}

\begin{abstract}
This study presents the Fractionation, crystallization and hydrogenation of peppermint under specific conditions and studies the properties of each fraction. Peppermint oil and its constituents and derivatives are used in food, pharmaceutical and perfumery and flavoring industry. From this study it was observed that crystallization consumed more time and energy. Hydrogenation of the low value DMO using Ni catalyst gave good conversion but the use of high temperature and high pressure with $\mathrm{H} 2$ gas showed their disadvantages. The use of IPA as the solvent also contributed to its quality. It was observed that hydrogenation of DMO using sodium borohydride at room temperature with water as solvent was more efficient as compared with IPA and a mixture of IPA and water and it was found to be more economical.
\end{abstract}

Keywords : Crystallization, Hydrogenation, Peppermint Oil, Fractionation.

\section{Introduction}

Essential oils are products or mixtures of products which are formed in cytoplasm and are normally present in form of tiny droplets between cells ${ }^{1}$. They are volatile and aromatic. From a chemical point of view essential oils are mixtures of fragrant substances or mixtures of fragrant and odorless substances ${ }^{2}$. A fragrant substance is a chemically pure compound, which is volatile under normal conditions and which owing to its odor can be useful to the society. Plants in the mint family have been used for medicinal purposes since before $2000 \mathrm{BC}$, but menthol was not isolated until 1771. Menthol, a monoterpene isolated from various mints, is a topical pain reliever ${ }^{3}$.

Peppermint oil is obtained from the leaves of the perennial herb, Mentha piperita L. and M. arvensis var. piperascens a member of the Labiatae family ${ }^{4}$. It is a colorless, pale yellow or pale greenish-yellow liquid which is freely soluble in ethanol. Peppermint oil contains characteristic odor and taste. The solution may show opalescence. The oil is found on the undersides of the leaves, is extracted by steam distillation and is generally followed by rectification and fractionation before use.Mint oil and its constituents and derivatives are used in food, pharmaceutical and perfumery and flavoring industry. Its main constituent, menthol, is used in 
the manufacture of lozenges, toothpastes, pain balms, cold balms etc. Leaves of Mentha arvensis plant are raw material of peppermint oil.The oil is used for treating certain stomach disorders like indigestion, gas problem, acidity, etc. The oil is a natural source of menthol, which is the main ingredient of cough drops and ointments like Vicks Vapor rub, etc.

The official oil is required to contain from $4.5-10 \%$ of esters calculated as methyl acetate, not less than $44 \%$ of free alcohols calculated as menthol and $15-32 \%$ of ketone calculated as menthone ${ }^{5}$. Variations in the different components can affect the quality of the oil and gas chromatography can be used to analyze the different components $(30-40$ peaks) and hence quality of the oil. Japanese peppermint oil is derived from Mentha canadenis var. piperascens and it contains $70-90 \%$ menthol, for the extraction of which it is largely used. Dried peppermint leaf is used in herb teas, either on its own or in mixtures. Peppermint tea is regarded as a stimulant, a cure for flatulence and has antiseptic properties. It is used in treating indigestion, sore throats, colds and toothache; among others. The present work deals with the study of Peppermint Oil, Mentha piperita, involving the extraction of menthol by different methods and comparison of their odor profile.

\section{Experimental}

\section{Materials and Method}

Peppermint oil was procured from Symrise India Pvt Ltd. All the chemicals used were of analytical grade confirming to the specifications.

\section{Physical analysis of extracted watermelon seed oil}

Color, Refractive Index and Specific Gravityof Peppermint oil was determined by following AOAC (1998) method $^{6}$.

\section{Chemical Analysis of extracted watermelon seed oil}

Acid value (AV) was determined according to procedures in AOCS method ${ }^{7}$.

\section{Estimation of Total Alcohol}

$10 \mathrm{ml}$ of the essential oil was acetylated with $20 \mathrm{ml}$ of acetic anhydride in the presence of $2 \mathrm{~g}$ of anhydrous sodium acetate in the flask fitted with an air condenser. The excess acetic anhydride was converted to the acid by heating for $15 \mathrm{~min}$ after the addition of water. The acetic acid was separated from the acetylated product in a separating funnel. The aqueous layer was rejected and the acetylated layer was washed free of acid using brine washing followed by dilute bicarbonate solution wash. Finally washed distilled water, dried over anhydrous $\mathrm{Na} 2 \mathrm{SO} 4$ and filtered. The acetylated product was then saponified with alc. $\mathrm{NaOH}$ and excess alkali was estimated with std $\mathrm{Hcl}$.

The percentage total alcohol was calculated according to the formula,

$\%$ total alcohol $=\mathrm{AM} / 561-0.42 \mathrm{~A}$

where,

$A=$ sap value after acetylation

$\mathrm{M}=$ molecular weight of menthol

\section{Fractional Distillation}

The given sample of peppermint oil was fractionated by fractional distillation under reduced pressure $15 \mathrm{~mm}$ of $\mathrm{Hg}$ and temperature ranging upto $215^{\circ} \mathrm{C}$ using a fractionating vigreux column of $1 / 2$ feet in height and diameter by distilling only the oil without leading water into the retort. The column was attached to a reflux head which was further attached to an effective condenser and absolutely air tight joints were provided. The distillation was carried out by providing heat using a heating mantle, rate of heating $60 \mathrm{~W} / \mathrm{m} 2$ and at total reflux. A Perkin's triangle was used to provide vacuum supply to the system. Peppermint oil contains mainly menthyl acetate, menthol and menthone. A batch of $225 \mathrm{~g}$ was fed into the retort. The fractions were collected at different temperatures and were analyzed to estimate their chief constituents ${ }^{8}$. 


\section{Crystallization}

The Peppermint oil was refrigerated for $2-3$ days at temperature of $5^{\circ} \mathrm{C}-10^{\circ} \mathrm{C}$. The crystals are separated from the oil by vacuum filtration. The filtration was carried out using Whatman filter paper. By applying a vacuum of $15 \mathrm{~mm} \mathrm{Hg}$, the crystals were separated from the main oil. The crystals obtained were weighed and analysed using GC. The De- Mentholised oil (DMO) was further fractioned to study the constituents by GC analysis 9

\section{Hydrogenation}

Hydrogenation of De-mentholised oil was done after crystallization. To increase the commercial value of DMO, hydrogenation of the oil was done to obtain Menthol. However, hydrogenation was the chemical method to isolate menthol from the fraction. Hydrogenation was done by 2 different methods.

\section{Hydrogenation using $\mathrm{Ni}$ - catalyst}

$230 \mathrm{ml}$ of the sample oil was taken in the four necked flask. $5.5 \mathrm{~g}$ of the catalyst was weighed and added into the flask along with IPA as solvent. $\mathrm{H} 2$ gas was purged into the reactor. The temperature controller was set to $180^{\circ} \mathrm{C}$. Continuous stirring was provided along with controlled heating. After every $1 \mathrm{hr}$ the sample was withdrawn and the GC analysis was done to check the completion of the reaction. After 8hrs that is after the completion of the reaction, the mixture was allowed to cool. The catalyst was separated from the mixture by vacuum filtration. Later the catalyst was washed dried and it could be re-used. Further analysis of the reduced oil was done by checking their specific gravity and refractive index ${ }^{10}$.

\section{Hydrogenation using NaBH4}

$10 \mathrm{~g}$ of oil sample was weighed in a $100 \mathrm{ml}$ flat round bottom flask. $100 \mathrm{ml}$ of IPA was diluted with water and added to it. Solvent system was differed by varying the concentration of water and IPA. This mixture was left for stirring on the magnetic stirrer for $10 \mathrm{~min}$. Meanwhile, Sodium borohydride was weighed. NaBH4 was added pinch wise for nearly 30 minutes. Liberation of hydrogen was observed by the effervescence formation. After completion of addition the mixture was refluxed for $1 \mathrm{hr}$. The excess NaBH4 was neutralized with $6 \mathrm{M}$ HCL till the hydrogen formation stopped within the reaction and the $\mathrm{pH}$ was maintained at 12 . The product was recovered from the solvent system by refluxing and distilling out the solvent. Further analysis of the product was done by specific gravity, refractive index and $\mathrm{GC}^{11}$.

\section{Gas Chromatography}

Gas chromatographic analyses were performed by injecting $1 \mu \mathrm{L}$ of the oil solution in the split less

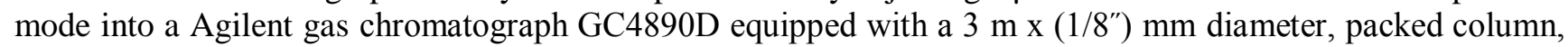
liquid- 3\% OV17, Solid- CHW-HP. The column was operated with hydrogen as carrier gas $(1 \mu \mathrm{L} \min -1)$ at an initial temperature of $75^{\circ} \mathrm{C}$ which was then raised at $5^{\circ} \mathrm{C} / \mathrm{min}$ to $230^{\circ} \mathrm{C}$. The injector was kept at $280^{\circ} \mathrm{C}$, and the flame ionization detector was set at $250^{\circ} \mathrm{C}$. Chromatograms were displayed and integrated.

\section{Result and Discussion}

\section{Analysis of raw material}

Table no: 5.1 Analysis of Raw Materials

\begin{tabular}{|l|l|l|}
\hline Properties & Results & Reported Data \\
\hline Color & Light, Pale Yellow & Pale Yellow \\
\hline Odor & Characteristic & Minty, Characteristic \\
\hline Refractive Index & 1.4578 & 1.457 to 1.467 \\
\hline Specific Gravity & 0.8967 & 0.8912 to 0.916 \\
\hline Acid Value & 1.359 & 1.4 \\
\hline Alcohol Content & $91.8 \%$ & $93 \%$ \\
\hline GC Analysis- \% Menthol & $73.1 \%$ & $75-80 \%$ \\
\hline
\end{tabular}

The properties were studies as shown in Table No: 5.1. The main constituent was Menthol 
contributing to maximum percentage in the oil mixture. The general analysis of oil was compared with the literature survey. The oil had a pale yellow color giving a minty characteristic odor which was much similar to the reported data. The specific gravity was 0.8967 which was within the range of $0.8912-0.916$ as per the reported data. The refractive index 1.4578 also showed positive remarks with the literature data which was within the range of 1.457-1.467.

The chemical properties were also studied during the process. It showed that the acid value obtained was 1.359 and the reported data was 1.4 and the alcohol content was observed to be $91.8 \%$ and as per the reported data it was shown as $93 \%$. Further analysis of the oil was done by Gas chromatography determining that the menthol content in the oil obtained from the market had $73.1 \%$ menthol content whereas it was reported to have $75-80 \%$ mentholcontent.

\section{Fractional Distillation of Peppermint oil}

Table no: 5.2 Analysis ofFractions

\begin{tabular}{|c|c|c|c|c|c|}
\hline $\begin{array}{c}\text { Fraction } \\
\text { no. }\end{array}$ & Amount (g) & $\begin{array}{c}\text { Head } \\
\text { Temperature } \\
(\mathbf{0} \text { C) }\end{array}$ & Specific Gravity & Refractive index & $\begin{array}{c}\text { GC-\% } \\
\text { Menthol }\end{array}$ \\
\hline 1. & 79 & $198-202$ & 0.891 & 1.4502 & 47.8 \\
\hline 2 & 43 & $202-205$ & 0.8926 & 1.4521 & 61.1 \\
\hline 3 & 7.3 & $205-207$ & 0.8942 & 1.4538 & 64.5 \\
\hline 4 & 5.5 & $207-209$ & 0.8975 & 1.4552 & 72.7 \\
\hline 5 & 2.3 & $209-210$ & 0.9017 & 1.4585 & 79.2 \\
\hline Residue & 86 & - & 0.9039 & 1.4629 & 76.08 \\
\hline
\end{tabular}

Fractional distillation of the oil obtained from the market was done using a $1 / 2$ feet Vigreux Column, $3.5 \mathrm{~cm}$ in diameter and pressure of $15 \mathrm{~mm} \mathrm{Hg}$. The fractions were collected at different temperatures. The temperature ranged from $195{ }^{\circ} \mathrm{C}$ to $212^{\circ} \mathrm{C}$. As shown in table no: 5.2 , the $1^{\text {st }}$ fraction was collected at $198^{\circ} \mathrm{C}$ $202^{\circ} \mathrm{C}$, second fraction at $202^{\circ} \mathrm{C}-205^{\circ} \mathrm{C}$, third fraction at $204^{\circ} \mathrm{C}-207^{\circ} \mathrm{C}$, fourth fraction at $207^{\circ} \mathrm{C}-209^{\circ} \mathrm{C}$ and the fifth fraction at $209^{\circ} \mathrm{C}-210^{\circ} \mathrm{C}$. By using a Vigreux column, the separation was done according to their volatility. Those constituents with a low boiling point appeared tocome in the first few fractions. However it was noticed that since Menthol had a higher boiling point compared to the other constituents, the isolation of menthol was done towards the end of the fractional distillation.

From Table no: 5.2, the specific gravity kept increasing from the first fraction (0.891) to the fifth fraction (0.9039) thereby showing the increase in the menthol content in the fractions. The refractive index also showed a drastic increase from the first fraction (1.4502) to the fifth fraction (1.4629) showing the presence of menthol content. However, the purity of menthol could be judged from their specific gravity and refractive index. More precise analysis was done using Gas chromatography, showing the increase in menthol content.

\section{Crystallization}

Table No: 5.3 Experimental Results after crystallization

\begin{tabular}{|l|l|}
\hline $\begin{array}{l}\text { Weight of sample initially taken } \\
\text { for refrigeration }\end{array}$ & $310 \mathrm{~g}$ \\
\hline Time for refrigeration & 3 days \\
\hline Temperature & $-20^{\circ} \mathrm{C}$ \\
\hline Amount of Crystals obtained & $13 \mathrm{~g}$ \\
\hline Yield (Menthol Crystals) & $13.9 \%$ \\
\hline De-mentholised oil- Mother & $255 \mathrm{~g}$ \\
\hline
\end{tabular}




\begin{tabular}{|l|l|}
\hline 1. Color & Colorless \\
\hline 2. Odor & Minty strong, cooling \\
\hline 3. Shape & Prism shaped or needle shaped \\
\hline 4. M.P & Above $42-43^{\circ} \mathrm{C}$ \\
\hline 5. Flavor & Cool sensation in mouth, characteristic mint flavor \\
\hline
\end{tabular}

Crystallization is an old technique for the extraction of Menthol. Industries have adopted this menthol for commercial purposes. According to the conditions in table no: 5.3, the sample oil after being kept in the refrigerator for 3 days was filtered using vacuum filtration at $15 \mathrm{~mm} \mathrm{Hg}$. The amount of crystals obtained were $13 \mathrm{~g}$ contributing to only $13.9 \%$.

The analysis of the crystals was done as shown in table no: 5.4. The crystals formed were thin, long needle colorless structures. It had strong minty, cooling effect which had much similarity with the natural menthol. Its melting point was observed to be $42^{\circ} \mathrm{C}-43^{\circ} \mathrm{C}$.

\section{Fractionation of De-Mentholised oil}

Table no:5.5Analysis of Fractionated DMO

\begin{tabular}{|l|l|l|l|l|l|}
\hline Sl.No & Amount(g) & $\begin{array}{l}\text { HeadTemp. } \\
\left({ }^{\circ} \mathbf{C}\right)\end{array}$ & $\begin{array}{l}\text { Specific } \\
\text { Gravity }\end{array}$ & $\begin{array}{l}\text { Refractive } \\
\text { index }\end{array}$ & $\begin{array}{l}\text { GC-\% } \\
\text { Menthol }\end{array}$ \\
\hline 1. & 12 & $176-177$ & 0.885 & 1.4285 & 0.004 \\
\hline 2 & 9.1 & $177-183$ & 0.887 & 1.413 & 0.058 \\
\hline 3 & 12.5 & $183-188$ & 0.889 & 1.4145 & 0.051 \\
\hline 4 & 17.8 & $188-191$ & 0.8909 & 1.4517 & 0.05 \\
\hline 5 & 2.9 & $191-193$ & 0.8927 & 1.4538 & 0.121 \\
\hline 6 & 14.9 & $193-196$ & 0.8951 & 1.4521 & 0.523 \\
\hline 7 & 15.3 & $196-200$ & 0.8867 & 1.4152 & 10.47 \\
\hline 8 & 19.8 & $200-202$ & 0.8894 & 1.4539 & 1.75 \\
\hline 9 & 25.3 & $202-205$ & 0.909 & 1.465 & 30.12 \\
\hline Residue & 67.3 & - & 0.911 & 1.461 & 2.1 \\
\hline
\end{tabular}

Fractionation of the De- mentholised oil was done using a Vigreux column of $1 / 2$ feet long, 3.5 in diameter under vacuum pressure. The fractions were taken at different temperatures as shown in table no.5.5. The fraction with the minimum fraction was obtained under vacuum at $176^{\circ} \mathrm{C}-177^{\circ} \mathrm{C}$. Better fractionation was obtained after the removal menthol. The minor constitutents could be well isolated. The second fraction was out within the range of $177^{\circ} \mathrm{C}-183^{\circ} \mathrm{C}$. The third fraction was separated at $183-188^{\circ} \mathrm{C}$. The fourth fraction was separated within the range of $188-191^{\circ} \mathrm{C}$ and fifth fraction was within the range of $191-193^{\circ} \mathrm{C}$. Their odor profile for each fraction varied as temperature kept rising. Moreover the fractions when analyzed showed better purity than being separated directly from the main extracted oil as per table no: 5.2. The sixth fraction was taken at $193-196^{\circ} \mathrm{C}$ and next fraction at $196-200^{\circ} \mathrm{C}$. The last two fractions had higher traces of menthol content which were taken at temperature $200-202^{\circ} \mathrm{C}$ and $203-205^{\circ} \mathrm{C}$.

Further analysis of each these fractions were done by determining their specific gravity, refractive index and Gas chromatography analysis as shown in table no: 5.5. The specific gravity kept increasing as the temperature kept increasing that is with respect to the first fraction to the last fraction. The initial fraction had 0.885 and the last fraction separated at $202-205^{\circ} \mathrm{C}$ had specific gravity 0.909 . However, during the separation of the seventh fraction at $196-200^{\circ} \mathrm{C}$, the decrease in the specific gravity was observed from 0.8951 to 0.8867 . The reason for this was due to the presence of more of menthone, isomenthone and other constituents. Further drastic increase from obtained for the last two fractions from 0.8867 to 0.909 . The measure of refractive index also increased from 1.4285 to 1.461 showing its closeness to the presence to menthol in the mixture. Gas chromatography showed large traces of menthol and their isomers in last fewfractions. 
Table No: 5.6 Analysis of hydrogenated Oil using Ni Catalyst

\begin{tabular}{|c|c|c|l|c|}
\hline Batch No: & \%(catalyst/substrate) & $\begin{array}{l}\text { Specific } \\
\text { Gravity }\end{array}$ & R.I & $\begin{array}{c}\text { \% } \\
\text { Conversion }\end{array}$ \\
\hline 1 & $1 \%$ & 0.887 & 1.4541 & 54.31 \\
\hline 2 & $2 \%$ & 0.892 & 1.4557 & 75.59 \\
\hline 3 & $3 \%$ & 0.895 & 1.4578 & 88.5 \\
\hline
\end{tabular}

Table no: 5.7 Analysis of Hydrogenated oil with NaBH4

\begin{tabular}{|l|ll|l|l|l|l|}
\hline SL.No. & $\begin{array}{l}\text { Weight of } \\
\text { Oil(g) }\end{array}$ & NaBH4 (g) & Solvent (ml) & R.I & $\begin{array}{l}\text { \% } \\
\text { conversion }\end{array}$ \\
\hline 1. & 10 & 0.605 & $\begin{array}{l}\text { Water }-50 \\
\text { IPA }-50\end{array}$ & 1.4586 & 76.32 \\
\hline 2. & 10 & 0.605 & $\begin{array}{l}\text { Water }-40 \\
\text { IPA }-60\end{array}$ & 1.4352 & 89.68 \\
\hline 3. & 10 & 0.605 & IPA- 100 & 1.4539 & 92.35 \\
\hline 4. & 10 & 0.605 & $\begin{array}{l}\text { Water }-60 \\
\text { IPA- 40 }\end{array}$ & 1.4633 & 94.17 \\
\hline 5. & 10 & 0.605 & Water -100 & 1.4567 & 96.7 \\
\hline
\end{tabular}

Hydrogenation was done by two techniques and the difference in their conversions and the quality of Menthol obtained were analysed.

\section{Hydrogenation Using Ni-Catalyst}

The reactions were conducted so that the maximal conversion of the starting substances would be achieved. For this reason, a partial hydrogen pressure $(1 \mathrm{~atm})$, high temperature $\left(200^{\circ} \mathrm{C}\right)$, solvent IPA and a great amount of a catalyst related to the substrate were used. The reaction was carried out for 6-8 hrs. The stirring of the reaction was maintained at $300 \mathrm{rpm}$. Menthone and isomenthone molecules get adsorbed on the catalyst by means of their chair conformation. Adsorption thus proceeds from the less restrained equatorial carbonyl side, where hydrogen approaches also from the catalyst surface. This way, the axial hydroxyl group is produced. If the produced alcohol remains longer on the catalyst surface, as a result of the adsorptiondesorption equilibrium stabilizing, the molecular orientation may change in relation to the catalyst surface. If this process lasts a sufficient period, it leads to formation of the equilibrium mixture, which contains primarily equatorial alcohol. Experimentally, it was proved that the faster the hydrogenation, the more of the axial alcohol is produced. The main reaction depended on the reactant getting adsorbed on the catalyst surface. It also depended on the concentration of $\mathrm{H} 2 \mathrm{gas}$.

There were three phases that existed during the reaction: organic liquid phase, solid phase- catalyst and the gas phase- $\mathrm{H} 2$ gas. Experiments were done to study the effect of solid- liquid mass transfer by varying the catalyst to substrate ratio. From Table no: 5.6, as the catalyst to substrate ratio increased from $1 \%$ to $3 \%$, their specific gravity increased from 0.887 to 0.8953 . The increase in the refractive index from 1.4541 to 1.4578 determined its closeness to the formation ofmenthol.

After the completion of the reaction, the product was separated from the catalyst by vacuum filtration. GC analysis proved the conversion of the product. From Figure: 5.1, it was evident that as the catalyst to substrate ratio increased, the conversion also increased from $54.31 \%$ to $88.5 \%$. The time was maintained as the possibility of formation of the isomers could have increased. The conversion was affected due to the adsorption of IPA on the catalyst active centers. However, IPA had less effect on the substrate solvation since better conversions were observed. If solvent had varied, it would have affected the adsorption of the substrate onto the catalyst active sites and thus resulted in less output.

\section{Hydrogenation Using NaBH4}


The reduction of the de-mentholised oil using Sodium borohyride involved the preliminary formation of the metallo-organic complex between the carbonyl group and the hydride species. The solvent in this system are water and isopropyl alcohol. IPA was used as a solvent as well as hydride source which added to the reduction process. For every one equivalent of $\mathrm{NaBH} 4$ there are four equivalents of hydride to react. The mechanism for the reduction involved the transfer of hydride ions from $\mathrm{NaBH} 4$ to the carbon of the carbonoxygen double bond. The variation in the solvent system, showed difference in the fragrance and the cooling effect of the menthol formed. In this compound, the isopropyl group occupies a position which flanks the carbonyl carbon very nearly equally on each side of the molecule. The variations in the stereoisomeric composition of the products were more dependent on thermodynamic and kinetic contributions in the reaction. When an equal mixture of water and IPA (50:50) was incorporated in the system, it was observed that the conversion was found to be nearly $76.32 \%$. Further when the ratio of water to IPA was changed as 40:60, the refractive index increased to 1.4352 and the conversion obtained was $89.68 \%$. The results have been summarized in the table no. 5.7. The use of IPA and water showed the stability variance. When only IPA was used as the solvent, the conversion increased to $92.35 \%$. Later a combination of water and IPA were used in the ratio 60:40. In this case, there was seen a better conversion of $94.17 \%$ and it was analyzed by GC the formation of neomenthol showing that the reduction occurred at the axial position (unstable site). However, in case of only water, the conversion was $96.7 \%$. It was observed that using Water alone higher conversion led to menthol and isomenthol showing the reduction has occurred at equatorial position (stable site). But with the addition of water to IPA the formation of axial group decreased. However, better results were obtained by the addition of water with IPA due to the steric approach. The polarity of the solvents also contributed to the difference in the conversion and selectivity.

\section{Conclusion}

Fractionation of peppermint oil and the de-mentholised oil under specific conditions enabled the methodology to determine the content of menthol and study the properties of each fraction. Crystallization consumed more time and energy, and the menthol crystals obtained required better storage and transportation facility which ultimately increases its cost. Hydrogenation of the low value DMO using Ni catalyst gave good conversion but the use of high temperature and high pressure with $\mathrm{H} 2$ gas showed their disadvantages. The use of IPA as the solvent also contributed to its quality as it did not affect the adsorption onto the catalyst active sites thus resulting in better conversion. It was observed that hydrogenation of DMO using sodium borohydride at room temperature with water as solvent was more efficient as compared with IPA and a mixture of IPA and water and it was found to be more economical.

\section{References}

1. M.M. Sonwa, Isolation and Structure Elucidation of Essential Oil Constituents, Department of Organic Chemistry, University of Hamburg (2000).

2. K. Anupam, Sachan, S. Kumar and A. Sachan, J. Scientific Res., 46, 194 (2010).

3. K. Husnu Can Baser, Gerhard Buchbauer, Handbook of Essential Oils-Science, technology and Applications, Taylor and Francis Group, pp.121-184 (2010).

4. A.G. Bayer, DrBurkhardt Stock, Prof. Dr. Ulrich Schlottmann, Menthols, UNEP publications, OECD SIDS, 2002.

5. P. Gardiner, Peppermint (Menthapiperita), [online] Longwood Herbal Task force: http://www.mcp.edu/herbal/, revised May 2, (2002)

6. AOAC, Official Methods of Analysis of AOAC International, Association of Official Analysis Chemists International, CD-ROM, 1998.

7. AOAC, Official Method of Analyis, $17^{\text {th }}$ ed., Association of Official Analytical Chemists, USA (2000).

8. A. Antonelli and C. Fabbri, Chromatographia, 49, 125 (1999); doi:10.1007/BF02575273.

9. V.M. Talati and Mukherji, Indian Oil Soap J., 26, 137 (1960), C.A 618123 E (1964). 
10. D.L. Manuale, C. Betti, A.J. Marchi, J.C. Yori and E. Romeo, Quim. Nova, 33, 1231 (2010); doi:10.1590/S0100-40422010000600002.

11. H. Haubenstock and Ernest L. Eliel, Reductions with Metal Hydrides- Solvent effect on the stoichiometry of reduction with sodium borohydride, University of Notre dame, Vol. 84 (1962).

$* * * * * * * * * *$ 